\title{
THE MIXTURES OF 2.4-DINITROPHENYLHIDRAZONES OF INFERIOR CARBONYL COMPOUNDS AND THEIR HPLC SEPARATION WITH GRADIENT BINARY MIXTURES PHASES
}

\author{
Gheorghe Zgherea \\ Department of Chemistry, Faculty of Sciences, University "Dunărea de Jos" of Galați \\ 111 Domnească street, 800.201 Galați, Romania, phone +40236 414871, fax +40236461353 \\ gzgherea@chem.ugal.ro
}

\begin{abstract}
Mixtures of small quantities of carbonyl compounds are presents in foods, concerning sensorial qualities. The inferior carbonyl compounds $\left(\mathrm{C}_{2}-\mathrm{C}_{4}\right.$, boiling point $\left.<100^{\circ} \mathrm{C}\right)-$ mono and dicarbonyl - can be identified and measured their concentrations, after a separation by distillation on the water bath. They are transferred in a strongly acid solution of 2.4-dinitrophenylhidrazine (2.4-DNPH), generating a mixture of insoluble 2.4-dinitrophenylhidrazones (2.4-DNPH-ones). The 2.4-DNPH-ones are organic compounds with weak polarity, solids, crystallized, yellows and water insoluble, soluble in organic solvents. The mixture of 2.4 dinitrophenylhidrazones may be separated by liquid chromatography, using the reverse phase mechanism [1-3]. This paper contains experimental and theoretical considerations to the means of separation through liquid chromatography of two synthetically and a natural mixtures that contain 2.4-DNPH-ones provided by inferior carbonyl compounds; to obtain conclude results, in the synthetically mixtures was introduce and 2.4-DNPH-ones provided by carbonyl compounds having three (acetone and propanal) and four (isobutyl aldehyde) atoms of carbon.
\end{abstract}

Keywords: acetic aldehyde, diacetyl, 2.4-dinitrophenylhidrazone, reverse phase, low polarity, gradient of mobile phase

\section{Introduction}

In many case, for the foods obtained by fermentation, it is very important to know the concentration of diacetyl and acetic aldehyde. Accordingly the literature, in beer there is diacetyl and acetic aldehyde in ratio 1:100. The interest on diacetyl concentration needs especially analytical conditions. It is possible to solve that problem by HPLC for the mixtures of 2.4-DNPH-ones provided by inferior carbonyl compounds. HPLC can be made a good separation only for the synthetics mixtures of 2.4-DNPH-ones; the molecules of inferior carbonyl compounds have the same physical and chemical behavior [4]. The difficult appears for the natural mixtures of carbonyl compounds. The difficult is greater if the ratio between quantities is too low. To have a good analytical performance, need to use liquid chromatography separation with gradient of mobile phase [5].

\section{Results and Discussion}

The synthetic mixtures $\left(\mathrm{SM}_{\mathrm{I}}\right.$ and $\left.\mathrm{SM}_{\mathrm{II}}\right)$ and a natural mixture from beer were separate by liquid-chromatography, using a mechanism of reverse phase.

Conditions of chromatographic separation

Injection volume: $10 \mu \mathrm{L}$;

Column: Spherisorb 5 ODS with gradient of stationary phase $(\mathrm{L}=25 \mathrm{~cm}, \Phi=4.6 \mathrm{~mm})$;

Temperature of separation column: $37.5^{\circ} \mathrm{C}$;

LC UV detector: $\lambda=355 \mathrm{~nm}$;

Flow rate: $1 \mathrm{~mL} / \mathrm{min}$.

Eluent: a mixture of A-methanol and B-water, accordingly to two programs realized by the LC-XPD module. The liquid-chromatographic separations

Both categories of liquid-chromatographic separation were realized on the same column, at the same temperature, changing only the program on mixing of liquids in binary mixture of mobile phase.

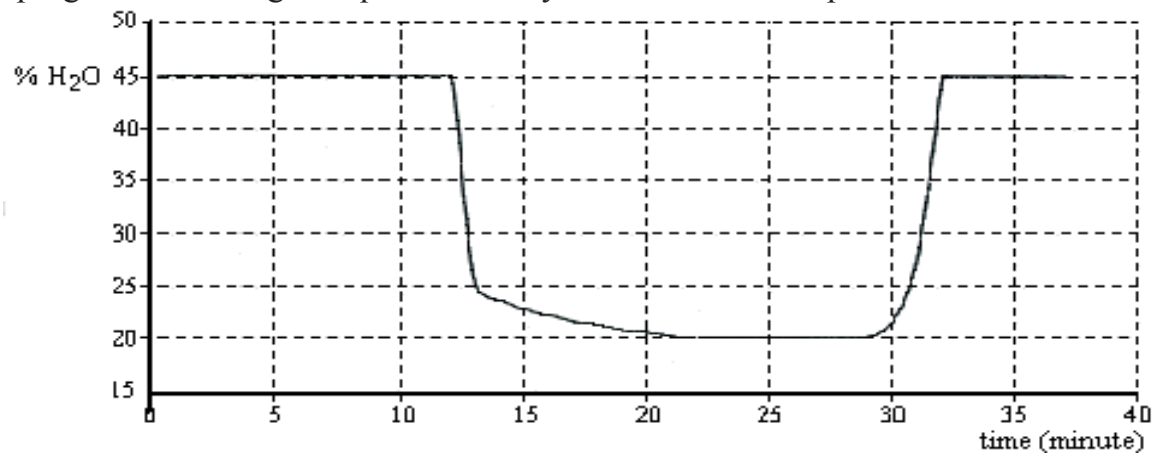

Figure 1. The program of GBMP 
The mixtures of mobile phase has the same initially composition, with $45 \%$ water. In this instance, the 2.4-DNPHAA will be eluted before the 2.4-DNPHD. This way is guaranteed the maximum difference between the values of retention times for the mentioned 2.4-DNPH-ones and a preliminary separation of the 2.4-DNPH-ones with three and four atoms of carbon. The synthetic mixture $\mathrm{SM}_{\mathrm{I}}$ contains four 2.4-DNPH-ones in the following ratio of volume:

$$
\text { 2.4-DNPHAA: 2.4-DNPHD: 2.4-DNPHA: 2.4-DNPHiBA = 2:1:1:1. }
$$

The first program of binary mobile phase, $\mathrm{BGMP}_{\mathrm{I}}(32$ minutes, figure 1), contains four time segments; in figure 2 there are the chromatogram of synthetic mixture $\mathrm{SM}_{\mathrm{I}}$, obtained with $\mathrm{BGMP}_{\mathrm{I}}$.

According $\mathrm{BGMP}_{\mathrm{I}}$, the separation begins with a mobile phase having $45 \%$ water; the mixture of mobile phase has a higher polarity. This mixture is hold during the first time segment, $\mathrm{g}=1(\mathrm{t}=12$ minutes), assuring a better resolution between the signal of 2.4-DNPHAA $(844 \mathrm{~s})$ and the signal of 2.4-DNPHD (918 s). The weak polar molecules of two 2.4-DNPH-ones are strongly retained on the no polar stationary phase. Therefore, the longitudinal diffusion of concentrated zone is lower. Simultaneously, on the stationary phase are strongly retained the 2.4-DNPH-ones provided by acetone and i-buthanal.

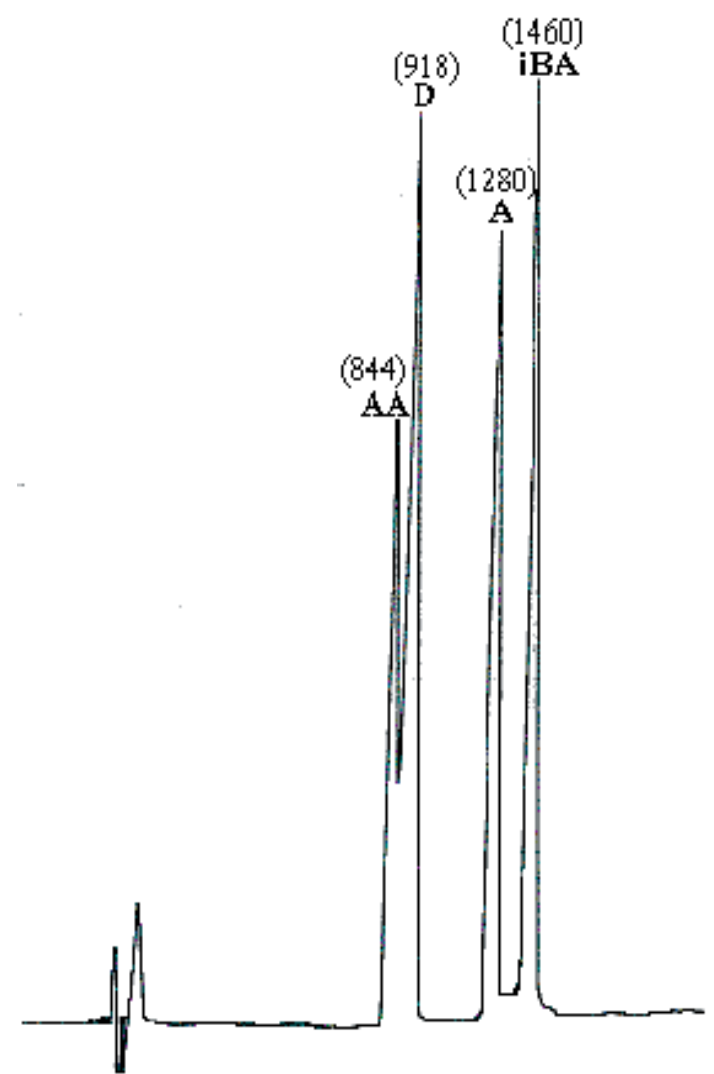

Figure 2.

The chromatogram of synthetic mixture abbreviate $\mathrm{SM}_{\mathrm{I}}$ AA is the chromatographic signal for the 2.4-DNPHAA and 844 is the retention time, in seconds;

$\mathrm{D}$ represents the chromatographic signal for the 2.4-DNPHD and 918 is the retention time (seconds);

A represents the chromatographic signal for the 2.4-DNPHA and 1280 is the retention time (seconds);

iBA represents the chromatographic signal for the 2.4-DNPHiBA and 1460 is the retention time (seconds).

On the second timing segment, $g=2(t=10 \mathrm{~min}, \mathrm{n}=0.1)$, the percent of water will be reduce at $20 \%$, thus the polarity of mobile phase subside; the 2.4-DNPHAA and 2.4-DNPHD (more soluble in organic solvent) diffuse in the mobile phase and will be transported to the end of separation column. On the third timing segment, $\mathrm{g}=3$ ( $\mathrm{t}=5 \mathrm{~min}, \mathrm{n}=1$ ), the percent of water is constant (20\%), to assure the best separation of 2.4-DNPHA and 2.4-DNPHiBA. The last timing segment, $\mathrm{g}=9(\mathrm{t}=5 \mathrm{~min}, \mathrm{n}=5.5)$, is destined to recondition stationary phase, for a new separation; all the timing segments $\mathrm{g}=4-8$ are inactive.

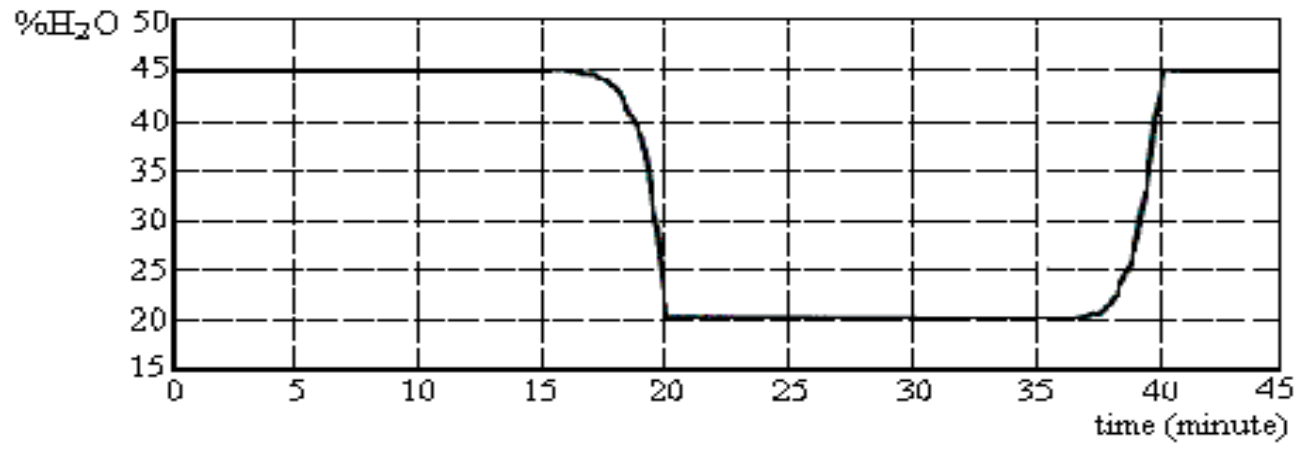

Figure 3. The program of GBMP 
The second program of binary mobile phase, $\mathrm{BGMP}_{\mathrm{II}}$ (40 minutes, figure 3), contains four time segments too; in figure 4 there are the chromatogram of synthetic mixture $\mathrm{SM}_{\mathrm{II}}$, obtained with $\mathrm{BGMP}_{\mathrm{II}}$. The synthetic mixture $\mathrm{SM}_{\mathrm{II}}$ contains the same 2.4DNPH-ones as $\mathrm{SM}_{\mathrm{I}}$, in the ratio of volume:

\section{4-DNFHAA: 2.4-DNFHD: 2.4-DNFHA: 2.4-DNFHiBA $=4: 1: 5: 5$.}

As in previous case, the first timing segment, $\mathrm{g}=1$ ( $\mathrm{t}=15 \mathrm{~min})$, the mixing program assures an eluent with $45 \%$ water, for the best separation between 2.4-DNPHAA and 2.4-DNPHD; the polarity of mobile phase is higher (the molecules of 2.4-DNPH-ones are strongly retained on the stationary phase).

The second timing segment, $\mathrm{g}=2(\mathrm{t}=10 \mathrm{~min}, \mathrm{n}=9.9)$, the percent of water is reduced at $20 \%$; this value is constant and during the third timing segment, $\mathrm{g}=3(\mathrm{t}=15 \mathrm{~min})$. Subside of mobile phase polarity produce a desorbtive process from the stationary phase. The timing segments, $g=4-8$ haven't got a specific content. In the last timing segment, $g=9$ $(\mathrm{t}=5 \mathrm{~min}, \mathrm{n}=0.1)$ quickly rebuilds the initial mixture of mobile phase; at the finish, the analytical system is completely ready to a new separation.

Comparing the chromatograms from figures 2 and 4, may be concluded that the $\mathrm{BGMP}_{\mathrm{I}}$ assure a better separation for the 2.4-DNPHAA and 2.4-DNPHD; for the 2.4-DNPHA and 2.4-DNPHiBA, the resolution is comparable.

The figure 5 is a chromatogram of a natural mixture of 2.4-DNPH-ones, for the inferior carbonyl compounds of beer. The liquid-chromatographic separation is on the same column and the eluting program $\mathrm{GBMP}_{\mathrm{I}}$.

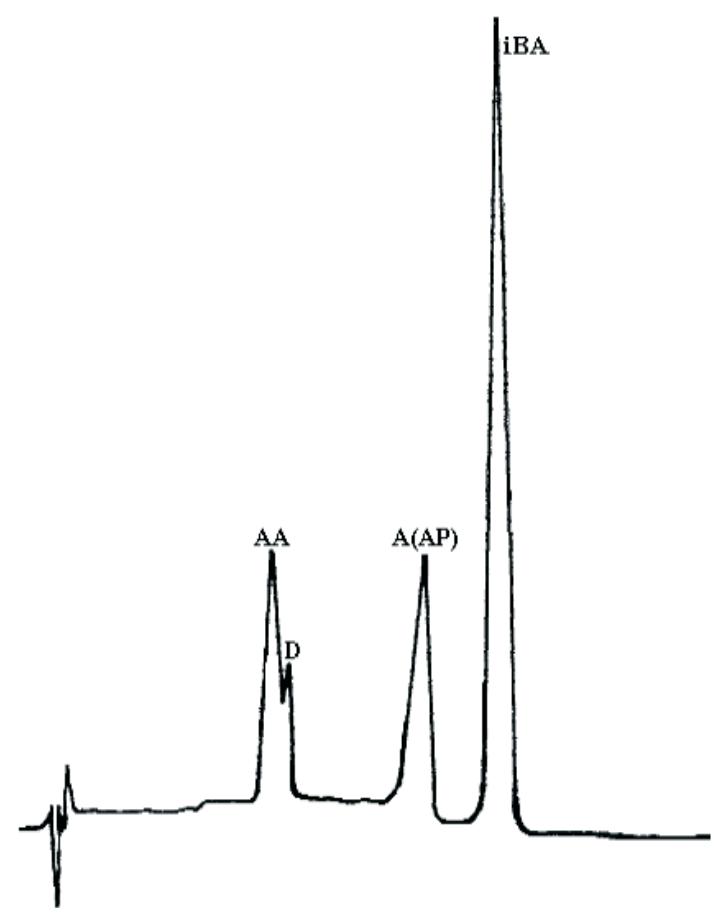

Figure 4.

The chromatogram of $\mathrm{SM}_{\mathrm{II}}$

AA - chromatographic signal for the 2.4-DNPHAA;

D - chromatographic signal for the 2.4-DNPHD;

A - chromatographic signal for the 2.4-DNPHA

(after the same retention time appear the signal for propanal);

iBA - chromatographic signal for the 2.4-DNPHiBA.

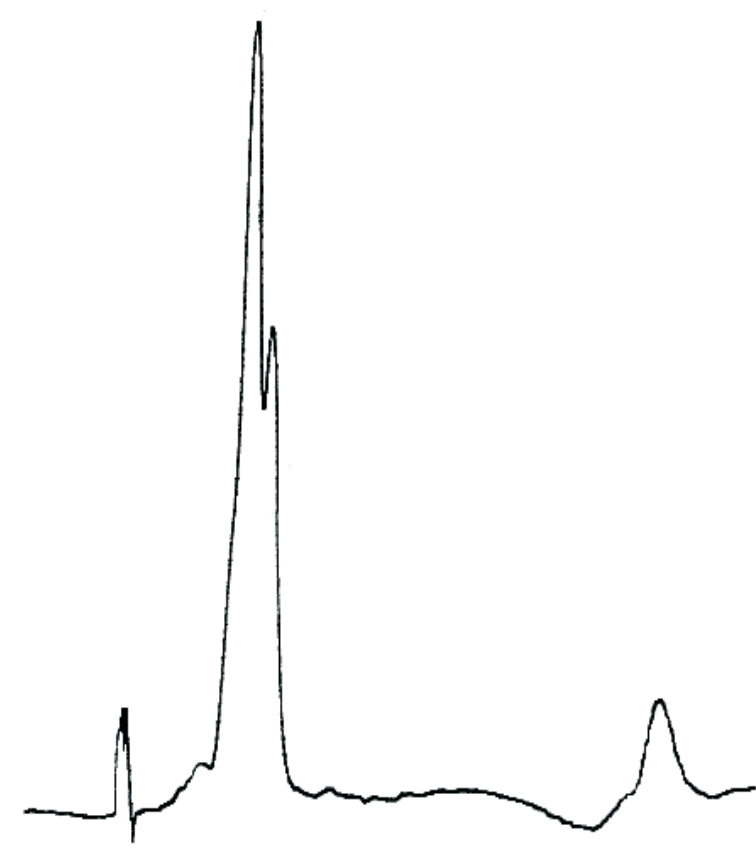

Figure 5.

The chromatogram of natural mixture of 2.4-DNFH-ones

Using the external standard method, for the chromatographic signal of 2.4-DNPHAA, obtain $14.75 \mathrm{mg} \cdot \mathrm{L}^{-1}$ as concentration of acetic aldehyde in beer; the value is in concordance with the literature. The surface of chromatographic signal of 2.4-DNPHD offer a value of $2.5 \mathrm{mg} \cdot \mathrm{L}^{-1}$ as concentration of diacetyl in beer; this value is higher. In beer, the normal values of diacetyl concentration is $0.01-0.2 \mathrm{mg} \cdot \mathrm{L}^{-1} ; 0.15 \mathrm{mg} \cdot \mathrm{L}^{-1}$ is the threshold value.

\section{Conclusions}

On the basis of these experiments may be formulating the following conclusions:

1. Was established two optimal programs for providing mixtures of binary eluent; according them, it is provided 
two mixture of binary phase that assure liquid-chromatographic separation, with a good resolution, for the synthetically mixtures of 2.4-DNPH-ones provided by the carbonyl compounds with 2-4 atoms of carbon.

2.The binary mixtures of mobile phase, obtained by the programs $\mathrm{GBMP}_{\mathrm{I}}$ and $\mathrm{GBMP}_{\mathrm{II}}$, assure a better separation of synthetic mixtures witch contain the derivate compounds of inferior carbonyl compounds; in these synthetic mixtures the ratio between 2.4DNPHAA and 2.4-DNPHD is higher than one, but very low.

3.In the case of natural mixtures of 2.4-DNPH-ones, similarly with synthetic mixtures, the binary mixtures of mobile phase offer only partially analytical satisfaction. Thus, the figure 5 contains evident the dominant peak of 2.4-DNPHAA. Using his surface value for quantitative appreciation by external standard method, obtain experimental values accordingly with the literature, namely $15 \mathrm{mg} \cdot \mathrm{L}^{-1}$ acetic aldehyde [6]. In the same chromatogram, the peak of 2.4DNPHD there is the second, but the second one is on the tailing peak of the first one. On the natural mixture of 2.4DNPH-ones on might make the following consideration: if the literature offer the real concentration values for the two carbonyl compounds, the accuracy of analytical system will justified by the big value, $\sim 100$, of the ratio between the quantities of acetic aldehyde and diacetyl. In this instance, the little peak of 2.4-DNPHD appears as a tailing peak on the big peak of 2.4-DNPHAA, thus, his surface is higher than the normal one; the mistake value of surface chromatographic signal became a source of mistake value of concentration.

4.Each chromatogram - figures 2, 4, and 5 - contains any signals with lower values of retention time; it is the signals for solvent.

\section{Experimental}

Solvents and mobile phases

The acetonitrile was utilized to solve the pure 2.4-DNPH-ones. To liquid-chromatographic separations was utilized two binary gradient mixtures of mobile phase $-\mathrm{GBMP}_{\mathrm{I}}$ and $\mathrm{GBMP}_{\mathrm{II}}-$ with water $\left(2 \mathrm{~S} \cdot \mathrm{cm}^{-1}\right)$ and $\mathrm{methanol}$ (Merck).

The synthetic mixtures of 2.4-DNPH-ones

The pure 2.4-DNPH-ones - yellow powders - are obtained in our laboratory, using 2.4-DNPH and chemical pure carbonyl compound; thus: 2,4-DNPHAA (acetic aldehyde), 2.4-DNPHD (diacetyl), 2.4-DNPHA (acetone), 2.4-DNPHP (propanal) and 2.4-DNPHiBA (isobutyl aldehyde). Their purity was verified by: elemental analysis, IR spectrophotometry and liquid-chromatographic separations. In acetonitrile (Merck, pro liquid chromatography) were obtained $5 \cdot 10^{-4} \mathrm{M}$ solutions. By controlled mixing was obtained two synthetic mixtures, abbreviated $\mathrm{SM}_{\mathrm{I}}$ and $\mathrm{SM}_{\mathrm{II}}$; the ratio between the quantities 2.4-DNPHAA and 2.4-DNPHD is higher to one, in each mixture.

The natural mixtures of 2.4-DNPH-ones

The carbonyl compounds from beer were separate by distillation on the water bath and transferred in 2.4DNPH, acid solution; the precipitates form a natural mixture of 2.4-DNPH-ones. They are isolated by filtration, washing with pure water, drying and solved in acetonitrile.

Apparatus

For the separations was utilized Pye Unicam Philips liquid chromatograph, equipped with: an installation for degassation of mobile phase (by refluxation) [7], gradient programmer for mobile phase (type LC-XPD, able to mix two liquids), separation columns with gradient of stationary phase, installation for column thermostatation, electronic integrator (type DP101) and potentiometric recorder (type PM8251). The mixing program of liquids has nine segments of time, $g=1-9$; each timing segment has independent dimension of 0-99 minutes. In every moment, the value of $\mathbf{B}$, the percent of the second component in the mixture of mobile phase $(\mathbf{A}+\mathbf{B}=100)$, is

$$
\% B=k \cdot t^{n}
$$

where, $\mathrm{t}$ - dimension of timing segment (minutes), $\mathrm{k}$ - slope of curve (describes the evolution of $\mathbf{B}$ value on the $\mathrm{t}$ segment), $\mathrm{n}$ - exponent, with values 0.0-9.9 (describes the geometry of mixing curve).

\section{References}

[1] Simion Gocan, Cromatografie de Înaltă Performanță, Partea a II-a, Cromatografia de Lichide pe Coloane, Editura RISOPRINT, Cluj-Napoca, 2002, pp 173-183.

[2] Douglas A. Skoog, Principles of Instrumental Analysis, Third edition, Saunders College Publishing, 1985, pp 801-815.

[3] Candin Liteanu; Simion Gocan; T. Hodisan; H. Nascu, Cromatografia de Lichide, Editura Stiintifica, Bucuresti, 1974, pp 156-157.

[4] Radu Bacaloglu; Carol Csunderlik ; Livius Cotarcă; Hans-Horst Glatt, Structura şi Proprietățile Compuşilor Organici, volumul I, Editura Tehnică, Bucureşti, 1985, pp 116-127.

[5] Gort S.M., Hogendoorn E.A.; Dijkman E.; Van Zoonen P.; R. Hoogerbrugge, The Optimisation of Step-Gradient Elution Conditions in Liquid Chromatography, Chromatographia, vol. 42, No 1/2, ian 96, pp 17-24.

[6] *** BIERANALYSE 9.11 Bestimmung der Gärungsneben produkte in Bier, pp 246-250.

[7] Gheorghe Zgherea, Installation to Continuously Degassation by Refluxing of Mobile Phases for HPLC, Annals of West University of Timişoara, series Chemistry 12 (3) (2003) pp 1157-1160. 